\title{
NORMA SEXUAL Y COMPORTAMIENTOS COTIDIANOS EN LOS DIEZ PRIMEROS AÑOS DEL FRANQUISMO: NOVIAZGO Y SEXUALIDAD
}

por

\author{
ANNE-GAELIE REgUEILLET \\ CIREMIA, Universidad François Rabelais, Tours
}

RESUMEN: Teniendo en cuenta el cambio politico y social que trajo la llegada del régimen franquista, se trata de definir el concepto de «norma sexual» comunicado por los productores del discurso oficial, y ver si influia en el comportamiento sexual de los individuos. Se ba centrado este estudio en la pareja durante los diez primeros años del franquismo, con objeto de determinar los tipos de comportamientos autorizados por la moral y la ley. En primer lugar, se examinan las diversas reformas discursivas, legislativas e institucionales que incitaron a verbalizar el sexo, y cuyo apogeo llegó en los años veinte, y más concretamente durante la segunda República española. Aunque la tesis más extendida sobre la verbalización del sexo afirma que ésta desapareció con la llegada del régimen franquista, pensamos que siguió existiendo, si bien a otro nivel. Se analiza la naturaleza del discurso oficial de los años cuarenta en la línea tradicional y se define el concepto de «pareja normal»: la pareja casada y procreadora. Posteriormente, se señala que el noviazgo era la única oportunidad legítima de tener relaciones íntimas antes del matrimonio. Se pasa revista a las diversas prácticas íntimas autorizadas por los productores del discurso oficial, y luego a las que se practicaban en la realidad cotidiana. Se subraya la complejidad del análisis de los comportamientos sexuales en los primeros años del Franquismo y todo lo que queda por explorar.

Palabras clave: Sexualidad. Norma sexual. Noviazgo. España. Primer franquismo.

ABSTRACT: Taking into account the political and social change brought by the Franco régime, this paper attempts to define the concept of "sexual norm» imparted by the producers of official discourse and to examine whether it influenced the sexual behaviour of individuals. The study concentrates on the first ten years of the régime and attempts to determine the types of sexual behaviour which were permitted by law and by the prevailing moral code. I shall first examine the reforms in discourse, law and institutions which promoted the public discussion of sexual matters which ocurred in the 
1920 s and culminated in the Second Republic. Although it is generally argued that the public discussion of sexual matters disappeared with the arrival of the Franco régime, in fact it continued to exist, albeit at a different level. There follows an analysis of the nature of official discourse in the 1940s which was traditionalist and defined the "normal couple» as the married couple with children. I shall then show bow only by being engaged to be married could a couple enjoy a sexual relationship before marriage. There follows a comparison between the intimate practices permitted by official discourse and those which occurred in everyday life. The. study emphasises the complexity of sexual practices in the early years of francoism and outlines the investigation which still remains to be done.

KEY WORDS: Sexuality. Sexual norm. Engagement to marry. Spain. Early francoism.

La guerra civil española y la llegada del régimen franquista representaron una ruptura evidente en la historia contemporánea española. La represión, entendida en su sentido general, condicionó, con distintas modalidades según los años, los lugares y los medios sociales, la vida de los españoles durante los treinta y seis años que duró la dictadura del general Franco. La tesis más extendida en torno al problema de la sexualidad define globalmente este periodo político como un periodo de «represión sexual» durante el cual el discurso sobre el sexo habría desaparecido del todo. A partir de un análisis de la pareja durante los diez primeros años del Franquismo, pretendemos demostrar que existía una verbalización del sexo e intentaremos definirla.

No se trata aquí de poner a prueba la tesis según la cual hubo una «represión sexual", sino de aproximarnos al tema de la verbalización del sexo durante el primer franquismo a partir de otro punto de vista, intentando contestar a las preguntas siguientes: ¿qué reprimía el régimen franquista? y ¿cuál era la naturaleza del discurso sobre la sexualidad?'1.

\section{REPRESIÓN DE LOS VALORES REPUBLICANOS Y MODERNOS}

A partir de los años veinte, muchos médicos e intelectuales impusieron una nueva concepción de la sexualidad e intentaron romper con la antigua moral sexual, tradicional y rígida, despertando un gran interés. «La vía editorial que Marañón inició con sus libros», observa así el editor de Biblioteca Nueva, "puso de manifiesto la difusa pero intensa curiosidad del gran público por la sexología»².

1 Ver REGUEILLET, Anne-Gaëlle: La sexualidad durante el franquismo: discurso pedagógico y realidades cotidianas, Tesis doctoral, dirigida por el profesor Jean-Louis GUEREÑA, Tours, Universidad François Rabelais, 2004.

2 Ruiz-Castillo Basala, José: Memorias de un editor. El apasionante mundo del libro, Madrid, Fundación Germán Sánchez Ruipérez, 1986, p. 212.

Hispania, LXIV/3, núm. 218 (2004) 1027-1042 
La Constitución republicana de 1931 permitió al respecto cambios radicales al aliviar la legislación, y en particular la que se aplicaba a la pareja y a la familia. En su conjunto, las reformas republicanas pretendían ensanchar las libertades individuales, disminuyendo por lo tanto el poder de la Iglesia católica sobre las instituciones y, mediante ello, el que tenía sobre las mentalidades y los comportamientos cotidianos.

La llegada del régimen franquista detuvo radicalmente el avance de estas reformas e impuso el retorno a la moral tradicional ${ }^{3}$. El nuevo régimen nació tras tres años de guerra civil, y necesitaba imponer una política represiva para conservar este poder obtenido mediante las armas y garantizar una estabilidad política y social. Los productores del discurso oficial de los años cuarenta veían en la Segunda República y en sus partidarios la causa de todos los males que sufría España, y particularmente de la guerra civil misma. En particular, la laicidad constituía, según ellos, el mayor "delito» cometido por la Segunda República, y explicaba la «decadencia» política y social que reinaría en España antes de la llegada del nuevo régimen.

Con el Franquismo, todos los sectores que auspiciaban la transmisión de los valores defendidos por los republicanos sufrieron por lo tanto una dura represión. El discurso sobre la sexualidad transmitido durante el Franquismo se inspiraba de hecho en todas las teorías, los modelos y los códigos contra los cuales intentó luchar la Segunda República. Los fundamentos de la moral franquista se inspiraban ampliamente en efecto en el tradicionalismo y en el catolicismo ${ }^{4}$.

Resulta, pues, necesario preguntarse si el primer franquismo fue realmente un periodo de retraimiento discursivo sobre el sexo en comparación con el periodo republicano - durante el cual se produjo un verdadero auge de las publicaciones relativas a la sexualidad, movimiento que pudo calificarse entonces como «marcha triunfal del sexo»`-, y si llegó al paroxismo la «represión sexual».

\section{NATURALEZA DEL DISCURSO SOBRE EL SEXO DURANTE EL PRIMER FRANQUISMO}

La amplia vulgarización del saber sobre el sexo - con sus múltiples obras y colecciones - que caracterizaba los años veinte y el periodo de la segunda República desapareció con la llegada del régimen franquista. Sin embargo, duran-

3 RIPA, Yannick: «Féminin/masculin: les enjeux du genre dans l'Espagne de la Seconde République au franquisme», Le Mouvement Social (París), $\mathrm{n}^{\circ}$ 198, enero-marzo de 2002, pp. 111-127.

4 Ver CABALlero, Óscar: El sexo del franquismo, Madrid, Editorial Cambio 16, 1977, 319 p.; EslaVA GALÁN, Juan: El sexo de nuestros padres, Barcelona, Editorial Planeta (Espejo de España 160), $1993,366 \mathrm{p}$

5 LlaURAdo, A. G.: «La marcha triunfal del sexo», Estudios, Valencia, nº 119, Juillet 1933, pp. 19-20. Ver AMEZÚA, Efigenio: "Cien años de temática sexual en España: 1850-1950. Repertorio y análisis. Contribución al estudio de materiales para una historia de la sexología», Revista de Sexología, Madrid, n 48, 1991, 197 p.

Hispania, LXIV/3, núm. 218 (2004) 1027-1042 
te aquellos diez primeros años de dictadura, siguió la difusión de algún saber sobre la sexualidad. En su tesis doctoral, Jesús Pérez López pudo catalogar así unos 214 manuales publicados entre 1939 y 1950, y un total de 536 libros editados entre 1939 y 1962, que tratan del tema de la sexualidad ${ }^{6}$. Y por ejemplo, en 1949, tan sólo un año después de la publicación original americana, se publicó en castellano la famosa encuesta titulada Sexual Behaviour in the Human Male realizada en los Estados Unidos por Alfred Kinsey [1894-1956] y sus colaboradores.

Más que un discurso represivo, el discurso franquista sobre el sexo era tradicional ${ }^{7}$. Con argumentos científicos y religiosos, el discurso oficial de los años cuarenta definía como finalidad exclusiva de la sexualidad la procreación, lo que justificaba la necesidad de la relación carnal entre hombres y mujeres. La especie humana no podía reproducirse sin sexualidad, y ésta se definía como una "necesidad biológica» a la que cada hombre y cada mujer tenía que someterse dentro del matrimonio canónico.

La sexualidad procreadora dependía del plano divino, cuyo objeto era poblar la tierra. A hombres y mujeres se les consideraba como colaboradores de Dios, y no se les autorizaba pues a que utilizasen la relación sexual con el único fin de gozar. Todos los comportamientos sexuales cuya finalidad no era la procreación eran calificados por lo tanto de aberraciones sexuales por el discurso oficial. No sólo ponían en peligro el individuo mismo, sino también toda la población. La censura franquista controlaba todos los elementos sociales que podían alejar a los individuos de esa «necesidad biológica» e incitarles a buscar placer mediante el sexo -cine, literatura, ideas políticas- y todos los lugares que facilitaban el encuentro y la promiscuidad entre los dos sexos: bailes, paseos, escuela.

La moral sexual y el postulado de procreación condicionaban esencialmente el comportamiento sexual femenino. La «doble moral», típica de los sistemas tradicionales, regía los comportamientos masculinos y femeninos, creando una desigualdad flagrante. La feminidad implicaba el pertenecer a un hombre único, y conservar por lo tanto la virginidad hasta el matrimonio. Se asociaba también a la maternidad y a la necesidad de procrear. Aquellos dos postulados condicionaban estrechamente los comportamientos femeninos y justificaban el control moral y social que se ejercía sobre las mujeres españolas en los años cuarenta ${ }^{8}$.

Aunque se aconsejara a los hombres que se quedasen castos hasta el matrimonio, ellos podían tener relaciones íntimas anteriormente, con prostitutas

6 PÉrez LóPez, Jesús: El discurso pedagógico relativo a la sexualidad (1940-1962), Madrid, Editorial de la Universidad Complutense de Madrid, 1993. Ver también del mismo «La iniciación sexual de la infancia durante el nacional-catolicismo. La propagación de la «verdad divina» frente a los errores de la calle», Revista de Educación (Madrid), nº 304, mayo-agosto de 1994, pp. 177-196.

7 Ver REDONDO, Augustin (Ed.): Amours légitimes, amours illégitimes en Espagne (XVI'-XVIr siècles), París, Publications de la Sorbonne, 1985, 414 p.

8 Ver, por ejemplo, AIZPúruA, Francisca de: iMujer! Tu destino, Barcelona, Ediciones Ariel, 1947, $271 \mathrm{p}$. 
por ejemplo, sin que ello impactase su probidad. Sin embargo, sería injusto imaginar que los varones españoles de los años cuarenta gozaban entonces de una total «libertad sexual». La sociedad les obligaba a comportarse «como hombres", es decir que se les pedía que demostrasen su virilidad tomando iniciativas hacia el otro sexo. Paradójicamente, se les consideraba responsables de la virginidad de las muchachas.

Como en todo sistema social tradicional, esta concepción de los comportamientos sexuales implicaba una división muy estricta de los papeles que cada sexo desempeñaba en el matrimonio y en la sociedad en general. La actividad social de las mujeres se concentraba en la esfera privada del hogar familiar: tareas domésticas («sus labores»), educación de los niños. La esposa era el sostén moral del hombre, dueño de la esfera pública y encargado de satisfacer las necesidades de su familia, de la cual era el jefe.

Otro punto permite definir la sociedad española de los años cuarenta como tradicional, o sea la concepción que se tenía del placer sexual:

«El punto clave para distinguir una mentalidad tradicional respecto al sexo (de otra que no lo es) consiste en la prohibición (o legitimidad) del goce sexual fuera de la función reproductora que lleva apajerada el «uso» del matrimonio»?.

El discurso oficial de los años cuarenta no condenaba pues el placer sexual en sí, sino cuando éste era la finalidad única de la relación sexual heterosexual, y cuando lo provocaba el individuo con prácticas sexuales naturalmente infecundas como la masturbación y la homosexualidad. Desde el punto de vista médico y moral, el gozo sexual no tenía nada malo cuando acompañaba la voluntad de procrear.

Dentro de la relación conyugal sacralizada por el matrimonio canónico, practicar la sexualidad no sólo constituía un derecho, sino un deber al cual los esposos tenían que someterse. La ausencia total de relación sexual entre los esposos —en caso de impotencia por ejemplo - era una de las razones que justificaban la anulación del matrimonio según el canón $\mathrm{n}^{\circ} 1.068$ del código canónico y el artículo $\mathrm{n}^{\circ} 101-1$ del código civil. Las normas ya citadas —obligación de procrear, gozo sexual limitado, iniciativas masculinas - también condicionaban la relación sexual matrimonial.

\section{PREVENCIÓN Y CASTIGO DE LAS TRANSGRESIONES SEXUALES HETEROSEXUALES}

La construcción cultural tradicional de la noción de sexualidad implicaba, pues, el reconocimiento de una norma sexual única: la relación sexual era lícita, normal y natural, sólo cuando se practicaba dentro del matrimonio y con el

9 De Miguel, Amando: Sexo, mujer y natalidad, Madrid, Edicusa, 1975, pp. 37-38. 
objeto de procrear. Todas las otras formas de sexualidad - extraconyugal, homosexualidad, masturbación, prematrimonial- se consideraban como aberraciones sexuales y perversiones del comportamiento.

El discurso de los años cuarenta se interesaba mucho por lo que concebía como transgresiones a la norma sexual. Mientras que los autores explicaban poco el funcionamiento de la sexualidad «normal», clasificaban todos aquellos comportamientos considerados «fuera de la norma», lo que creaba una diversidad de discursos sobre el tema de la sexualidad. Cada uno de aquellos discursos pertenecía a un esquema piramidal: la Iglesia poseía los fundamentos del saber sobre el sexo y distinguía las prácticas ilícitas de las normales; el discurso científico apoyaba y demostraba científicamente la veracidad de esas definiciones; la Justicia y la Moral se encargaban de castigar las transgresiones. La pareja legítima y procreadora se imponía como modelo y resultaba imposible elegir otro tipo de vida conyugal sin arriesgarse.

El Código civil reconocía dos tipos de matrimonio: el matrimonio civil y el matrimonio canónico. El segundo era obligatorio cuando las dos personas que deseaban unirse eran católicos. La Orden ministerial del 10 de marzo de 1941 pedía a las parejas deseosas de casarse sólo por lo civil que justificasen el no ser católicas mediante un certificado. Se puede imaginar que pocos usaron de aquel «derecho» ya que el no ser católico se asociaba con el republicanismo y era entonces sinónimo de traición política al nuevo régimen.

A pesar de la indisolubilidad del matrimonio civil y católico, en algunos casos la ley permitía la separación de cuerpos y bienes. Sin embargo, esa ley no ponía en cuestión la indisolubilidad de la unión matrimonial y no permitía a los cónyuges que se casasen con otra persona. Las segundas bodas no tenían ninguna existencia civil y, en este caso, el artículo 471 del Código penal condenaba a los culpables a la pena de prisión menor (entre seis y doce años de encarcelamiento).

La defunción de uno de los dos cónyuges era la única razón que permitía la disolución de la unión matrimonial. Pero la «doble moral» implicaba una legislación más dura para con las viudas. Ellas tenían que esperar trescientos y un días después del fallecimiento de su esposo antes de poder casarse con otro hombre ${ }^{10}$. Si no respetaban esta obligación, se arriesgaban a una multa importante (entre 1.000 y 5.000 pesetas). Además, según el Código civil de los años cuarenta, las viudas que deseaban casarse de nuevo conservaban la patria potestad sobre sus hijos, pero sólo cuando el marido le había dado su licencia antes de morir o en su testamento.

Con la ley del 11 de mayo de 1942 se restableció el delito de adulterio, suprimido durante la Segunda República con la reforma del divorcio en 1932. El artículo 449 del Código penal de 1944 condenaba a los culpables de adulterio a

10 Código Civil Español, Madrid, Instituto Editorial Reus, 1954, artículo n 45-2. 
la pena de prisión menor (entre seis y doce años de encarcelamiento) ${ }^{11}$. Dicho Código penal definía dos tipos de adulterio: el femenino y el masculino.

Efectivamente, sólo con tener alguna relación carnal con otro hombre que no fuese su marido, las mujeres eran culpables de adulterio:

«Art. 449: Cometen adulterio la mujer casada que yace con varón que no sea su marido, y el que yace con ella, sabiendo que es casada, aunque después se declare nulo el matrimonio» 12 .

Las mujeres sólo podían pertenecer físicamente a un hombre y la simple relación sexual hacía de ellas unas adulteras. En cambio, el esposo cometía este delito sólo cuando su amante vivía con él, o sea en el hogar familiar, con la esposa y los hijos, o cuando la relación que mantenía con su «querida» era conocida públicamente, lo que podía considerarse como motivo de escándalo público:

«Art. 452: El marido que tuviera manceba dentro de la casa conyugal, o notariamente fuera de ella, será castigado con prisión menor» 13 .

Las esposas no podían denunciar a su marido por adulterio cuando éste mantenía simples relaciones sexuales con otra mujer. La legislación les obligaba a demostrar la existencia de una vida común entre los dos amantes.

El Código penal condenaba sobre todo la sexualidad extraconyugal, lo que demuestra que este tipo de transgresiones a la norma sexual preocupaba mucho a las autoridades. Las relaciones íntimas antes del matrimonio no eran castigadas por las leyes sino en caso de «estupro» (artículos 434 a 437 del Código penal), o sea, según la definición facilitada entonces por el diccionario de la Real Academia, por «acceso carnal del hombre con doncella mayor de doce años y menor de veintitrés años, logrado con abuso de confianza o engaño» ${ }^{14}$.

Las relaciones sexuales antes del matrimonio no representaban pues un delito penal sino moral. Los médicos apoyaban la prohibición moral y demostraban científicamente la peligrosidad sanitaria de este tipo de relación. El delito moral lo provacaban las mujeres al perder su virginidad antes del matrimonio. Perdían a la vez su valor moral y su honestidad cuando necesitaban esas calidades para poder casarse y estar reconocidas socialmente. La sociedad española de los años cuarenta pretendía proteger la virginidad de las chicas y de las muchachas. Se las enseñaba que era el bien más precioso que poseían.

En las escuelas, se separaban a los alumnos en cuanto entraban en primer curso. Se suprimió por lo tanto la coeducación — sistema pedagógico adaptado

11 Ver ZalbideA, Víctor: El delito sexual en España 1944-1974, Madrid, Sedmay Ediciones, 1975, 227 p.

12 Código Penal Español, Madrid, Instituto Editorial Reus, 1949, p. 117.

13 Ibid, p. 118.

14 Diccionario de la Lengua española, Madrid, Real Academia Española, 1947, p. 570.

Hispania, LXIV/3, núm. 218 (2004) 1027-1042 
por el gobierno republicano- durante la guerra civil en todas las regiones que pertenecían a la zona nacionalista y, después de la victoria franquista, en todo el país.

Esta supresión se justificaba con la diferencia biológica existente «naturalmente» entre los dos sexos. Ésta implicaba lógicamente la existencia de dos psicologías, una femenina y una masculina, lo que impedía una enseñanza común. El discurso oficial predicaba pues la necesidad de una enseñanza adaptada a cada uno de los sexos, para que se desarrollasen las características femeninas y masculinas. La mezcla de los sexos resultaba peligrosa para el desarrollo de los individuos, conllevando una «masculinización» de las mujeres y una «feminización» de los hombres, aunque el primer peligro fuese más utilizado para justificar la separación de los alumnos en las escuelas.

Otra razón explicaba la necesidad de separar a los chicos y a las chicas: la moralidad y el respeto de la virginidad hasta el matrimonio. La ley sobre la escuela primaria del mes de julio de 1945 prohibía la coeducación a partir de los doce años. Antes de esta edad, cuando los recursos económicos de la región no permitían la creación de nuevos centros docentes, se podían mezclar con los niños con la condición de que el maestro fuese una mujer.

Según el discurso oficial, los doce años correspondían con el desarrollo del "instinto sexual», latente durante la infancia, y el principio de la actividad sexual. Era pues un periodo critíco durante el cual se necesitaba separar a los chicos y a las chicas para evitar toda tentación. La separación de los sexos desde la infancia era sólo un elemento en todo el sistema social de los años cuarenta, el cual intentaba evitar la promiscuidad entre mujeres y hombres.

Sin duda, la familia era la institución más afectada por el postulado de la virginidad femenina, ya que el perderla no sólo ponía en duda la honestidad de la muchacha misma, sino también la de la familia, y por consiguiente, la de los padres. Desde luego, las reacciones cambiaban según las familias, las clases sociales. Cuando una muchacha soltera confesaba su embarazo a sus padres, algunos la protegían escondiéndolo o ayudando al aborto o al infanticidio ${ }^{15}$. Al contrario, muchos padres decidían echar a la hija de casa para salvar el honor de la familia manchada por la deshonestidad de la muchacha.

Los chicos que tenían relaciones sexuales antes del matrimonio no eran culpables de nada, sino que afirmaban su virilidad. Muchos de ellos conocieron en efecto su primera experiencia sexual con una prostituta, sin que la sociedad les juzgase moralmente por ello ${ }^{16}$.

15 Ver Blasco HerranZ, Inmaculada: «Actitudes de las mujeres bajo el primer Franquismo: La práctica del aborto en Zaragoza durante los años 40", Arenal. Revista de historia de las mujeres (Granada), vol. 6 (1999), $\mathrm{n}^{\circ} 1$, enero-junio, pp. 165-180.

16 GUEREÑA, Jean-Louis: La prostitución en la España contemporánea, Madrid, Marcial Pons, 2003, pp. 415-430.

Hispania, LXIV/3, núm. 218 (2004) 1027-1042 


\section{EL NOVIAZGO: LA EXCEPCIÓN}

Mientras que la institución de la pareja legítima y procreadora definía la norma sexual de los diez primeros años del Franquismo, el noviazgo representaba otra forma de «vida conyugal» autorizada. Las prácticas íntimas durante el noviazgo gozaban en efecto de algún reconocimiento social:

«El noviazgo no ha sido, o no es, una fórmula para economizar sexualidad, sino la única o de las pocas oportunidades «legales» para atenuar la represión»17.

Durante los diez primeros años del Franquismo, la definición del término de noviazgo cambiaba según quien lo utilizaba. Según el discurso oficial, dos personas eran novios cuando ya se habían comprometido y se iban a casar, lo que justificaba la legitimidad de esta relación. Esta resultaba necesaria porque preparaba a los jóvenes enamorados a la vida matrimonial. Permitía conocer al otro, descubrir si sería capaz o no de asumir los deberes que implicaban el matrimonio, la maternidad y la educación de los hijos.

En la realidad cotidiana, la palabra noviazgo no implicaba nada oficial. Las palabras novio y novia designaban a la persona con quien se vivía una relación amorosa sin que se hubiera planteado formalmente la voluntad de casarse. Esta concepción del noviazgo en la vida cotidiana hacía que era posible vivir varios noviazgos antes de unirse para toda la vida. Sin embargo, los hombres tenían varias novias antes de conocer a su esposa, mientras que las mujeres solían casarse con su primer novio.

Varias etapas componían el noviazgo, «[...] la primera, más espontánea, cuando todavía el compromiso no se ha hecho oficial; y la segunda, cuando los novios son presentados a las respectivas familias» ${ }^{18}$. Esta doble definición del noviazgo implicaba dos puntos de vista sobre las prácticas íntimas durante este periodo de la relación amorosa.

Desde el punto de vista del discurso oficial, y más particularmente del moralista, el noviazgo desempeñaba una función social evidente y útil ya que preparaba los futuros esposos a la vida conyugal: era pues «la preparación al santo matrimonio» ${ }^{19}$. Esta finalidad del noviazgo implicaba una normalización del comportamiento entre los dos sexos antes de la boda. Un destino inevitable unía hombres y mujeres: encontrarse, quererse, casarse y procrear. El equilibrio de la sociedad, y su moralidad, dependían de aquella «sociedad» que formaba el matrimonio.

El discurso oficial insistía pues en la necesidad de pensarlo bien antes de comprometerse con alguien, ya que un «error» sería fatal. El tiempo del no-

17 Ferrándiz, Alejandra y Verdú, Vicente: Noviazgo y matrimonio en la burguesía española, Madrid, Cuadernos para el Diálogo, 1975, p. 26.

18 ESLAVA GALÁN, Juan: Coitus interruptus, Barcelona, Planeta, 1997, p. 176.

19 VIANA, Enciso: La muchacha en el noviazgo, Madrid, Ediciones Studium, 1959 (6 $6^{\mathrm{a}}$ ed.), p. 19. 
viazgo representaba un periodo precioso de aprendizaje. El matrimonio no podía satisfacer las necesidades o los deseos de los individuos, sino que ellos tenían que someterse a la función social de aquel sacramento: la procreación y la educación de los hijos. El vínculo matrimonial era indisoluble y eterno, y por ello, el noviazgo era la oportunidad de elegir "correctamente» al futuro cónyuge, y darse cuenta de lo que representaba la vida matrimonial. Los autores del discurso oficial proponían una serie de restricciones y de consejos que era necesario aplicar para conseguir un noviazgo perfecto y respetuoso de la norma sexual.

La elección del futuro esposo o de la futura esposa representaba una etapa muy delicada ya que condicionaba la futura relación conyugal, y el equilibrio de la «sociedad conyugal» que formaría la pareja una vez casada. El amor era considerado como uno de los elementos más importantes, ya que sin él era imposible obtener un equilibrio que durase toda la vida. El amor servía la finalidad del matrimonio porque suscitaba las ganas de unirse carnalmente con su cónyuge y pues la procreación. Sublimaba la relación sexual entre los esposos y la elevaba encima de la simple función de reproducción:

«El amor es condición psicoafectiva indispensable en el matrimonio, pues guía e ilumina la elección del consorte, facilita el cumplimiento de los deberes matrimoniales y dulcifica la vida en familia» 20 .

Sin amor, la relación perdía toda dimensión divina y espiritual y sólo llegaba a ser una manera cualquiera de satisfacer las necesidades del instinto sexual. Sin amor, la unión carnal entre los esposos se reducía a un simple instinto animal, faltando de dignidad. El matrimonio era primero y ante todo una unión espiritual entre dos personas. $Y$ eso lo tenían que aprender los futuros esposos durante el periodo del noviazgo. Pero el amor sólo se plasmaba con el matrimonio. Antes, y precisamente durante el noviazgo, los dos jóvenes tenían que aprender a reconocer este amor, y evitar confundirlo con una simple atracción, o peor, con una manifestación del deseo sexual:

«No basta que una mujer diga: «Este hombre me gusta»; para que aquel hombre sea la horma de su zapato o el rey de su corazón. No es suficiente que el joven diga: "Esta chica me enamora», para que pueda y deba ser la compañera de su vida» 21 .

El verdadero amor, explicaban los autores del discurso oficial, comenzaba por una amistad amorosa y suponía una templanza en las relaciones fisícas. Se basaba en una unión puramente espiritual, y en la complicidad, la ternura y la comprensión. El desear relación carnal con su novia o su novio daba la prueba de que el sentimiento experimentado para con el otro no era verdadero, sino

20 Vallejo Nágera, Antonio: Antes que te cases, Madrid, Editorial Plus-Ultra, 1946, p. 238.

21 García FigAr, Antonio: Yo tengo novio, Madrid, Editorial Bibliográfica Española, 1947, p. 20. 
fútil y superficial. Éste desaparecería poco tiempo después de la boda y no permitiría alcanzar el equilibrio necesario entre los cónyuges.

La finalidad precisa del periodo de noviazgo era por lo tanto «el conocimiento verdadero del futuro consorte» ${ }^{22}$. Según los autores del discurso oficial, en cuanto se sentía amor por alguien, lo primero que había que hacer era enterarse de quién era aquella persona. Por ejemplo, desaconsejaban el matrimonio entre dos personas que no proviniesen de la misma clase social, porque esa diferencia podría impedir la construcción del equilibrio conyugal.

El elegir a una persona implicaba el hecho de estar elegido también, y entonces había que adaptarse a los criterios que distinguían el buen consorte del malo. La «doble moral» definía los principios de la relación entre los dos sexos: discreción y pureza para las muchachas, actividad e iniciativas para los muchachos que tenían que galantearlas para conquistar su corazón. A los jóvenes que actuaban de forma demasiado directa o que querían obtener los favores sexuales de las chicas se les llamaba ligones. Las jóvenes no podían tomar ninguna iniciativa sin exponerse a recibir el calificativo de ser una chica fresca. Luchar contra la atracción del instinto sexual garantizaba pues el éxito de la futura unión matrimonial.

\section{LA SEXUALIDAD DURANTE EL NOVIAZGO}

El noviazgo se distinguía del matrimonio por un punto preciso: la finalidad del matrimonio era la procreación, lo que obligaba a la relación sexual. Ésta no desempeñaba ningún papel durante el periodo del noviazgo, y un embarazo antes del matrimonio solía poner fin a la relación amorosa. Los autores del discurso oficial prohibían desde luego toda forma de relación demasiado íntima y cariñosa durante el periodo del noviazgo. En efecto, las demostraciones de cariño ponían en peligro la pureza y la honestidad de las muchachas. Una simple caricia podía mancharlas.

Sin embargo, los autores, conscientes de la debilidad de la naturaleza humana, concedían el derecho a ciertas manifestaciones de cariño. Los besos en la cara (menos el beso en la boca que era considerado como pecado) y en la mano se clasificaban entre las demostraciones de cariño lícitas:

«No son igualmente pecado mortal ni venial aquellos besos limpios en las mejillas, frente y manos, con que los enamorados se regalan y fomentan su cariño, cuando se dan con limpieza, brevemente y en circunstancias especiales, como un encuentro, una despedida, un día grande, una fecha determinada, el día del santo»23.

22 Ibid., p. 18.

23 Ibid., p. 192. 
Como lo demuestra esta cita, el beso era lícito cuando emanaba de una voluntad de demostrar su ternura y su afecto para con la otra persona. Podían besarse los novios pero de forma excepcional. Cuando la atracción física originaba el deseo de besarse, el beso era peligroso. Por eso, los autores del discurso insistían en la necesidad de darse besos delante de los demás, pero íntimos o conocidos (la familia por ejemplo), y no a solas, o en lugares oscuros, situaciones que incitaban a una intimidad más fuerte:

«Ello se entiende dado sin escándalo ni furtivamente, sino a la luz del sol y ante la familia o amigos. El escándalo viene si se da en público o delante de niños o personas inocentes ${ }^{24}$.

Las prescripciones sobre el beso se atribuían también al abrazo, que era lícito sólo cuando se daba en las condiciones ideales, o sea delante de otras personas que podían vigilar. Los autores del discurso oficial acusaban todos los demás contactos físicos de fomentar la deshonra, y les consideraban como preliminares a más contactos, como el primer paso hacia el "pecado».

$\mathrm{Al}$ contrario de los autores del discurso oficial, la sociedad de los años cuarenta toleraba más las relaciones íntimas entre los novios. El beso en la boca, e incluso el beso profundo, se practicaban mucho durante el periodo del noviazgo. Era también la única manifestación de cariño que difundía el cine. Pero, paradójicamente, el beso en la boca representaba algo muy importante para algunas mujeres quienes a veces esperaban hasta seis meses de relación antes de aceptar el beso pedido por el novio. En algunos casos, que eran pocos pero reales, ciertas mujeres se imaginaban que podían quedarse embarazadas por haber dado o recibido un beso en la boca. En general, los novios solían besarse durante el noviazgo aunque no fuesen comprometidos. Lo hacían a escondidas, en los parques, en los portales, y más bien al anochecer.

$Y$, a pesar de la prohibición de los autores del discurso oficial, los novios solían acariciarse. Había dos tipos de caricias: las que se daban en lo alto del cuerpo, y las que se daban debajo de la cintura.

Hay pocas informaciones concretas que permiten describir exactamente las prácticas íntimas durante el noviazgo. En 1971, se publicó la primera edición de la encuesta realizada por el doctor Serrano Vicens sobre la sexualidad femenina, la cual nos facilita algunos datos concretos sobre este tema ${ }^{25}$. Entre 1932 y 1961, este médico cuestionó a 1.417 mujeres (entre las cuales 1.300 antes de 1953) que

24 Ibid.

25 SERRANO VICENS, Ramón: La sexualidad femenina Una investigación estadística, $1^{\mathrm{a}}$ ed., Barcelona, Pulso Editorial, 1971, 159 p., y La sexualidad femenina (Una investigación estadística y psíquica directa), 4ª ed., Gijón, Ediciones Júcar (Colección Apogeo/serie testimonio), 1976, 157 p. Ver también los testimonios reunidos en NIETO, José Antonio: La sexualidad de las personas mayores en España, Madrid, Ministerio de Asuntos Sociales, 1995, 501 p. 
eran pacientes suyas sobre su sexualidad. Las respuestas de aquellas mujeres permiten establecer qué tipo de relaciones íntimas se tenían antes del matrimonio.

El $95 \%$ de.las mujeres con las que Serrano Vicens trató afirmaron haber dado y recibido caricias antes del matrimonio. Las estadísticas del médico destacan una diferencia de actitud según el sexo. El $40 \%$ de aquellas mujeres acariciaron las partes genitales de su novio, mientras que el $60 \%$ se dejaron acariciar por él. Estos resultados demuestran el impacto de la «doble moral» sobre los comportamientos. A los hombres se les autorizaba tomar iniciativas cuando las mujeres tenían que guardar recato antes del matrimonio. Además, las representaciones del deseo y del placer sexual correspondían con la masculinidad y no con la feminidad. El $30 \%$ de las mujeres que se dejaron acariciar conocieron el orgasmo antes del matrimonio y antes de vivir una relación sexual completa, o sea con penetración. La estimulación oral se practicaba poco durante el noviazgo: el $2 \%$ de aquellas mujeres conocieron el cunnilingus y el $2,8 \%$ practicaron la felación.

El «toqueteo» - palabra empleada durante el primer franquismo para designar los intercambios de caricias, y que se puede comparar con el «flirteo» ${ }^{26}$ - se practicaba a escondidas pero fuera de la casa familiar, en los parques, a menudo cuando anochecía, para no captar la atención de los transeúntes. En el cine, las parejas aprovechaban la oscuridad y las butacas del fondo de la sala para acariciarse sin ser vistas por los demás. Allí, se acariciaban, se besaban, se masturbaban mutuamente. Las mujeres se solían dejar acariciar cuando la relación empezaba a durar y parecía seria, y a menudo porque el deseo del novio las incitaba a ceder.

Las prácticas íntimas que acaban de describirse eran aceptadas socialmente, es decir que la comunidad sabía que los novios se comportaban de esta forma, así como lo demuestra este refrán que solían cantonear las madres a su hijas: "Cuidado, besos y abrazos no dan niños, pero ya es la víspera»"

Pero la aceptación informal por la sociedad de estas prácticas íntimas no indica la posible existencia de una «libertad sexual» y no supone un impacto débil de la moral sobre el comportamiento de los españoles. La «doble moral» condicionaba las prácticas íntimas y las iniciativas no las tomaban las mujeres, sino los hombres.

Al contrario de los besos en la boca, de los abrazos y de las caricias, no se toleraba la relación sexual completa. Tanto los productores del discurso oficial como la sociedad la condenaban y la castigaban. El postulado de la virginidad y el miedo al embarazo hacían que los novios mismos no solían dejarse llevar por el deseo y la tentación. Según la encuesta del doctor Serrano Vicens, sólo el $32,5 \%$ de las mujeres interrogadas perdieron su virginidad antes de estar casa-

26 Ver CaSTA-Rosaz, Fabienne: Histoire du flirt. Les jeux de linnocence et de la perversité 18701968, Paris, Bernard Grasset, 2000, 352 p.

27 Testimonio oral obtenido en Valladolid en julio de 2000 de una mujer nacida en 1931.

Hispania, LXIV/3, núm. 218 (2004) 1027-1042 
das, y el $8 \%$ practicaron con su novio la juxtaposición de las partes genitales sin llegar a la penetración. En cambio, los hombres solían descubrir la sexualidad antes del matrimonio, pero casi siempre con otra mujer que la novia: prostituta, criada, chica fresca.

La institucionalización del noviazgo implicaba una normalización de los comportamientos íntimos y la vigilancia social de los lugares de encuentros. El reconocimiento oficial de la necesidad de un periodo de noviazgo antes del matrimonio abría un espacio legal y moral para que los hombres y las mujeres pudiesen verse y conocerse. Las diferentes etapas que componían el noviazgo se vivían ante el resto de la comunidad, o sea los amigos, los adultos, la gente en general. Sin duda, se vigilaban más los primeros pasos de la relación.

Desde luego, la sociedad española no facilitaba los contactos entre los sexos. Como ya se dijo, se suprimió la coeducación en las escuelas. Por otra parte, los autoridades prohibían la presencia junta de ambos sexos en determinados lugares públicos como en la piscina o en la playa. Sin embargo, según el discurso oficial, los hombres y las mujeres estaban hechos por conocerse, quererse, casarse y procrear, y para ello se necesitaban lugares de sociabilidad accesibles a los dos sexos.

Si la coeducación se prohibió en todas las escuelas primarias y en los establecimientos de enseñanza secundaria, la enseñanza universitaria siguió siendo mixta durante el primer franquismo, y muchachas y muchachos se juntaban en las aulas:

«Por la tarde, en el laboratorio de química en el que estudiábamos, había más relaciones entre los chicos y las chicas porque había que formar grupos de trabajo. Recuerdo una anécdota, en ese laboratorio, los chicos decían a menudo a las chicas: «Mañana, guapas, no os perfuméis tanto por favor». Es verdad que nos mareábamos con su perfume» 28 .

Fuera de la universidad, los alumnos solían reunirse en las cafeterías a las que grupos de chicas y chicas iban juntos. Algunas universidades organizaban bailes estudiantiles en los cuales no era imposible tener relaciones íntimas, y a veces relaciones sexuales completas. Pero no nos figuremos la universidad como un lugar en el que no tenía ningún impacto la moral sexual. Cuando dos estudiantes habían tenido relaciones sexuales, el peso de la moral les obligaba a quedarse mudos. Además, la universidad no permite tener una visión global de las relaciones intersexuales. No todos los jóvenes, y aún menos las jóvenes, podían seguir estudios superiores, y la universidad acogía a muchachos y muchachas procedentes de clases sociales medias o altas.

Intenso espacio tradicional de sociabilidad, la calle desempeñaba un papel muy importante en los encuentros entre los chicos y las chicas. Participaban en

28 Testimonio oral obtenido en Valladolid en 1999 de un hombre nacido en 1926.

Hispania, LXIV/3, núm. 218 (2004) 1027-1042 
lo que se podría considerar como un «ritual» cuyo objeto era buscar una novia o un novio: el paseo. Se practicaba en todas las ciudades, en las calles más importantes o en la Plaza mayor:

«En todas las ciudades españolas existía una calle principal o una plaza mayor donde a horas fijas tenía lugar la ceremonia, hoy en desuso, del paseo. [...] Por ejemplo, en la Plaza Mayor de Salamanca, las chicas paseaban en el sentido de las manecillas del reloj, mientras que los hombres lo hacían en el sentido contrario. Como quiera que el ritmo del paseo fuera más o menos el mismo en ellos y en ellas, generalmente lento, ya se sabía que por cada vuelta completa a la Plaza se iba a tener ocasión de ver dos veces a la persona con quien interesaba intercambiar la mirada, y hasta se podía calcular con cierta exactitud en qué punto se produciría el fugaz encuentro» 29 .

Aquel vaivén constante permitía a los jóvenes comunicarse discretamente con la persona que les gustaba. La mirada se hacía insistente, la sonrisa dulce, y cuando, por suerte, un amigo o una amiga conocía a la persona elegida, se podía entablar una conversación, furtiva, pero importante porque marcaba el primer paso hacia la relación amorosa.

Con el baile, los jóvenes españoles de la postguerra tenían también una oportunidad excepcional de entrar en contacto con el otro sexo. El baile implicaba un contacto físico directo y creaba una intimidad entre las dos personas. Abría muchas posibilidades para comunicarse, con personas ya conocidas durante el paseo, en la universidad o en otros sitios, pero dentro de un control constante y de muchas limitaciones ${ }^{30}$. El bastonero, «figura rescatada del olvido y obligatoria por entonces ${ }^{31}$, vigilaba a los bailadores y castigaba o echaba a las parejas cuyo comportamiento se consideraba indecente. Por otra parte, se reservaba a los hombres la posibilidad de expresar su atracción por alguien, ya que ellos invitaban a bailar a las mujeres. La decencia obligaba a las chicas a quedarse tranquilas, sin tomar iniciativas. Además, a menudo -en particular en los pueblos - iban acompañadas por sus madres, quienes las vigilaban.

La vigilancia social de las relaciones entre los chicos y las chicas se expresaba también mediante los padres quienes autorizaban la organización de los guateques. El guateque, «baile en casa particular con algo de comer y beber» ${ }^{32}$, se implantó en España a partir de los años cuarenta en las clases medias:

«La gente modesta y de clase media reunía en su casa, con las más estricta vigilancia, a un grupo de jóvenes de ambos sexos, dentro del ámbito familiar y

29 MARTín GAITE, Carmen: Usos amorosos de la posguerra española, Barcelona, Editorial Anagrama, 1994, p. 184.

30 Ver SAliCRÚ Puigvert, Dr. Carlos: ¿Es lícito bailar? Cuestiones candentes acerca de la moralidad pública, Segunda edición aumentada, Barcelona, Editorial La Hormiga de Oro, 1946, 71 p.

31 MariblanCa CaNeYro, Rosario: Bailar en Madrid (1833-1950), Madrid, Egraf, 1999, p. 216.

32 Ibid., p. 219 
vecinal, que bailaban la tarde de algún domingo o festivo a las compases de un tocadiscos, algunas veces alquilado, y que vino a ser el moderno substituto de organillos y orquestinas mientras que los niños topolino (distintivo por entonces de la «jet» juvenil) gozaban de más comodidades y libertad en sus hogares, y en ocasiones el hecho de bailar era un fútil pretexto para otras diversiones que comenzaban una vez consumidas varias combinaciones alcohólicas en el momento en que el atrevido de turno (previamente pactado) apagaba la luz...33.

A medida que la relación se hacía seria, los padres dejaban más libertad a la pareja de novios, y éstos podían pasear a solas, o ir al cine, al baile, sin que la chica necesitase «carabina», lo que suponía, o una confianza absoluta por parte de los padres, o una tolerancia explícita de las relaciones más íntimas entre los dos novios.

Se nota, pues, que las ocasiones de tener una vida de pareja eran relativamente pocas durante el periodo del primer franquismo, aunque el noviazgo diese libertad a los enamorados. Se ha tratado de analizar la pareja durante el primer franquismo a partir de un análisis de las prácticas autorizadas en el periodo del noviazgo. Este proceso implica la comparación entre el discurso oficial y las realidades cotidianas. A primera vista, no existían muchas diferencias entre lo que predicaban los productores de este discurso y los comportamientos cotidianos. Pero eso no significa que los comportamientos opuestos a la norma sexual de la pareja legítima y procreadora no existían. Lo ilustra, por ejemplo, este testimonio:

«Hacíamos el amor cuando yo volvía del trabajo. Un día estalló el preservativo pero seguimos la relación. Cuando me casé ya teníamos una hija de tres años» 34 .

Lo que cuenta este hombre demuestra la complejidad del estudio de la sexualidad durante el periodo del primer franquismo. Algunos comportamientos se adaptaban a los que defendía el discurso oficial, pero una parte de la población vivía su sexualidad independientemente de la norma sexual dominante. Una amplia documentación que queda sin estudiar cuestiona el lugar común de la «represión sexual» durante el primer franquismo y demuestra que esos comportamientos fuera de la norma merecen un estudio meticuloso.

33 Ibid., pp. 219-220.

34 Testimonio obtenido en Valladolid en el año 2000 de un hombre nacido en 1929. 